\title{
Reducing discomfort while measuring crown-heel length in neonates
}

\author{
LUIS PEREIRA-DA-SILVA ${ }^{1,2}$, KIM I. M. BERGMANS ${ }^{3}$, LIEKE A. S. VAN KERKHOVEN ${ }^{3}$, \\ FREDERICO LEAL ${ }^{1}$, DANIEL VIRELLA ${ }^{1} \&$ JOÃO M. VIDEIRA-AMARAL ${ }^{2}$ \\ ${ }^{1}$ Hospital Dona Estefania Maternity, Lisbon, Portugal, ${ }^{2}$ Department of Paediatrics, Faculdade de Ciências Médicas, \\ Universidade Nova de Lisboa, Lisbon, Portugal, and ${ }^{3}$ Radboud University Nijmegen Medical Center, Nijmegen, the \\ Netherlands
}

\begin{abstract}
Aim: To assess the degree of discomfort caused by length measurement in neonates, performed with one or both lower limbs extended, on the first and second day after birth, with either one or both lower limbs extended. Methods: Healthy full-term neonates were systematically sampled during the months of February and March 2004. Crown-heel length was measured, using a 1-mm precision neonatometer, at approximately $8 \mathrm{~h}$ and $32 \mathrm{~h}$ after birth, with one and both lower limbs extended. The Neonatal Facial Coding System was used to assess discomfort during measurements. Data were analysed by parametric and non-parametric tests as appropriate. Results: Whatever the measurement technique, discomfort scores are significantly higher during the length measurement than at baseline. Whenever length measurements are performed, discomfort scores are significantly higher when extending both lower limbs rather than one lower limb $(p<0.006)$. The measured length is greater with one lower limb extended; however, the difference decreases over time, being $0.19 \mathrm{~cm}(95 \%$ CI $0.1-0.3 ; p<0.001)$ at approximately $32 \mathrm{~h}$ of age. No significant differences in length were found between measurements at approximately 8 or $32 \mathrm{~h}$, regardless of the technique used. The best correlation between length measurements with one or both lower limbs extended was observed at approximately $32 \mathrm{~h}$ after birth $(r=0.98)$.
\end{abstract}

Conclusion: Measuring crown-heel length is a distressful procedure for the neonate. Measurements with one lower limb extended result in less discomfort than when both lower limbs are extended, without decreasing the accuracy.

Key Words: Length measurement, neonatal distress, neonate

\section{Introduction}

Length at birth provides important information regarding intrauterine growth and serves as a baseline for the assessment of postnatal growth [1-3]. Neonatal length measurement should be accurate, especially when included in indices used for nutritional assessment, wherein a small error in the length value may cause a significant distortion in the final result [4].

Following the conventional technique for neonatal crown-heel measurement, one person should hold the infant's head against the headboard of the neonatometer, whilst another person straightens both lower limbs and moves the footboard up against the heels firmly $[5,6]$. This method is dependent on achieving full lower limb extension of a neonate who is more comfortable in flexion [7]. As a result, accuracy may be influenced by the reluctance of the clinician to cause discomfort to the neonate, even by using gentle force when extending the lower limbs $[3,7]$. Some authors propose crown-heel measurement extending one lower limb, in order to reduce discomfort in the neonate [8]. However, discomfort caused by the full extension of the lower limbs has not been previously assessed with the aim to propose modifications in the conventional length measurement to reduce discomfort to the infant.

Shinwell et al. [3] found that the length increases significantly over the first few days after birth, and it was suggested that this was due to a decrease in the intrauterine state of flexion. Further studies are required to assess to what degree the state of intrauterine flexion may influence the crown-heel length measurement within the first days after birth.

The purposes of our study were 1) to assess potential discomfort during length measurement with one or both lower limbs extended, and 2) to evaluate whether there is any significant variation in measured length and discomfort within the first $2 \mathrm{~d}$

Correspondence: Luis Pereira-da-Silva, Hospital Dona Estefânia, NICU, Faculdade de Ciências Médicas, Universidade Nova de Lisboa, Rua Jacinta Marto, 1169-045 Lisbon, Portugal. Tel: +35 1213126613. Fax: +35 1217167203. E-mail: 1.pereira.silva@netcabo.pt 
after birth. The ultimate goal was to provide clinicians with an accurate method to assess neonatal crownheel length, while minimizing discomfort to the neonate.

We hypothesized that measuring crown-heel length with one rather than with both lower limbs extended causes less discomfort while providing an accurate measurement of neonatal length.

\section{Methods}

A systematic sample of healthy full-term neonates (37 to $41 \mathrm{wk}$ ), consecutively born between 21.00 and 03.00, at Hospital Dona Estefânia Maternity, Lisbon, Portugal, was included after parental consent. Neonates born by breech presentation, with a history of oligohydramnios, any clinical or laboratorial sign of disease, or maternal use of systemic opioids during pregnancy, labour or delivery were excluded from the study $[9,10]$.

A neonatometer manufactured for the maternity ward, with a precision of $1 \mathrm{~mm}$, was used to measure the recumbent crown-heel length [11]. During measurements, the subjects were naked in a supine position. Following the conventional technique, one observer (KB), the holder, positioned the infant's crown of the head up against the headboard of the neonatometer according to the Frankfort plan: the eyes facing upwards, and the lower margin of the orbit was in the same vertical line as the upper margin of the auditory meatus $[5,6]$. A second observer (LK), the measurer, extended the lower $\operatorname{limb}(\mathrm{s})$ completely by gently pressing the infant's knee(s) down, held the foot/feet vertically, at a right angle to the length board, moved the footboard up against the heel(s) firmly and registered the length. Measurements with one lower limb extended were always performed right sided and special attention was paid to always keep both trunk and limb axes parallel, and the line between the ileac crests at a right angle with the trunk axis. To avoid cumulative distress, the second measurement, with both lower limbs extended, was always performed after an interval of at least $3 \mathrm{~min}$ after the first measurement, with a single lower limb extended, during which the neonate was relaxed. For the subjects to be as comfortable as possible, it was assured that they were just fed and that the room had a comfortable temperature.

An adaptation of the Neonatal Facial Coding System (NFCS) was used to assess discomfort during crown-heel measurement $[12,13]$. This is an anatomically based scale, validated for bedside study of the pain behaviour of full-term neonates, in which the occurrences of 10 different facial actions are individually coded $[9,12,13]$. Tongue protrusion was omitted, as it is counter-indicative of pain in fullterm neonates [13]. Hence, nine facial actions instead of 10 were used. Two observers were trained by first performing the measurement procedures while discussing the facial actions as described in the scale. Then, they jointly performed the measurements and scored independently, until an inter-observer reliability of $>0.75$ was obtained and no systematic errors were found. During actual measurements, the two observers did not speak to each other while scoring, nor were they aware of the score given by the other. Each infant was scored simultaneously by both observers at each time.

Measurements were undertaken at two occasions: within $12 \mathrm{~h}$ after birth (T1) and $24 \mathrm{~h}$ afterwards (T2). At both times, three NFCS scores were obtained: at baseline (at rest, after undressing), with one lower limb extended, and with both lower limbs extended.

Data were analysed by parametric and non-parametric tests using the SPSS for Windows statistical package. The pairs of total NFCS scores obtained at each observational moment by both observers were analysed for homogeneity, using the Wilcoxon matched-pairs test and verifying inter-observer reliability. The inter-observer reliability of NFCS scores was computed for a randomly selected $20 \%$ of the subjects, for each face variable in each segment, using the conservative Facial Action Coding System reliability formula [14]:

$$
\begin{aligned}
& \text { Coefficient of reliability } \\
& =\frac{2 \times \text { No. of actions on which coder one and coder two agreed }}{\text { No. of actions scored by the two coders }}
\end{aligned}
$$

Homogeneity analysis was performed for the whole sample for demographic variables. Differences between length measurements were analysed using Student's $t$-test. Differences between NFCS scores were analysed using either the Wilcoxon test or the Mann-Whitney U-test, as appropriate. A correlation similarity coefficient matrix was used to study correlation among length measurements at different measurement times and by different measurement techniques.

\section{Results}

Seventy-one (39 male and 32 female) full-term neonates were included. The mean (range) gestational age was 39 (37-41) wk, birthweight 3299.7 (24304840) g, and Apgar score at 5 min 10 (8-10). Mode of delivery was spontaneous vaginal in $28(45 \%)$ neonates, vaginal forceps in five $(8 \%)$, and $29(47 \%)$ were born by caesarean section, mainly for obstetrical reasons. The proportion of male and female neonates was similar (Binomial test; two-tailed $p=0.5$ ).

Measurements (mean \pm SD) at T1 were performed at $8.0 \pm 3.5$ (range 3.7-14.8) h after birth and at T2 at $32.4 \pm 2.7$ (range 27.3-38.5) h after birth. At T1 and 
T2, respectively, $87 \%$ and $96 \%$ of the babies were awake after undressing.

\section{NFCS scores}

The inter-observer reliability of NFCS scores was 0.98. At every observational moment, the pairs of NFCS scores given by each observer were not statistically different; therefore, the average NFCS score of both simultaneous determinations was used for each baby.

The NFCS scores were significantly higher $(p<$ 0.001) during length measurement, whatever technique used, in comparison to scores at baseline. At both measurement occasions, discomfort scores were significantly higher $(p<0.01$ at both $\mathrm{T} 1$ and T2) extending both rather than one lower limb (Figure 1).

It was not possible to compare discomfort scores at $\mathrm{T} 1$ and $\mathrm{T} 2$, because the baseline score at T2 was significantly higher in comparison to $\mathrm{T} 1 \quad(p=0.03$; Table I). No significant differences between sexes were found on discomfort scores either at different ages or between different measurement techniques.

\section{Length measurements}

At approximately 8 and $32 \mathrm{~h}$ of age no significant differences in measured length with either one or both lower limbs extended were found. Length is greater if measured with only one lower limb extended: $0.24 \mathrm{~cm}$ at T1 $(95 \%$ CI $0.1-0.3 ; p<0.001)$ and $0.19 \mathrm{~cm}$ at T2 (95\% CI $0.1-0.3 ; p<0.001)$ (Table I).

Correlation similarity coefficients between length measurements with one or both lower limbs extended were $r=0.967$ at T1 and $r=0.983$ at T2 (Figure 2). Comparing length measurements at $\mathrm{T} 1$ and $\mathrm{T} 2$, correlation similarity coefficients were $r=0.881$ with one lower limb extended and $r=0.917$ with both lower limbs extended.

The correlation similarity coefficients were different between sexes: for measurements with one lower limb extended they were $r=0.953$ among females and $r=$ 0.781 among males, and for measurements with both lower limbs extended they were $r=0.961$ and $r=$ 0.863 , respectively.

\section{Discussion}

Of all the non-verbal acute pain indicators in neonates, facial expression appears to be the most consistent and relatively specific [9]. Not only does it differentiate pain from anger and sadness, for caregivers and nurses, it is also more consistent and salient than cries $[12,15,16]$. Additionally, in neonates, facial expression is a more sensitive response to painful procedures than cry, body movements or heart rate [17]. The NFCS is applicable at bedside, and it is easy to use in clinical practice by scoring the presence or absence of facial actions $[12,13]$. The NFCS is not really a graded scale, but it is very useful in assessing differences in discomfort and distress between various procedures. Assuming that crown-heel length measurement is a painful, non-invasive procedure in neonates [3,7], the NFCS was chosen to assess distress in this study [9]. An excellent inter-observer reliability (0.98) was obtained. Although assumed, the degree of distress in neonates caused by the forceful extension of lower limbs during crown-heel length measurement has not been previously assessed.

There has been a great deal of discussion in relation to the factors that may influence the accuracy and reliability of crown-heel measurement in newborns $[3,18,19]$. Since full extension is thought to cause

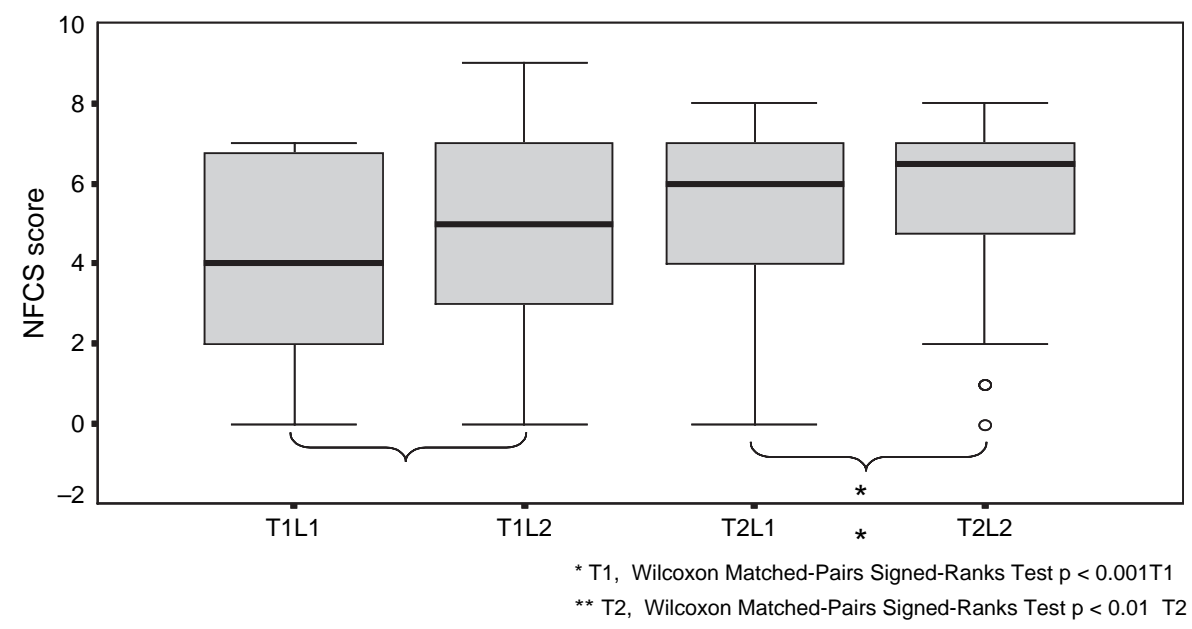

Figure 1. Change in discomfort (NFCS scores) during length measurement at approximately $8 \mathrm{~h}$ (T1) and $32 \mathrm{~h}$ (T2) of life, with one (L1) or both (L2) extended lower limbs $(n=71)$. Distribution box-plot graph: boxes represent central interquartile range of values; lines from the ends of the box ("whiskers") extend as far as the most extreme values not considered outliers. Points more than 1.5 times the interquartile range from the ends of the box are labelled as outliers $(\mathrm{O})$. 
Table I. NFCS scores and measurements at $8 \mathrm{~h}$ (T1) and $36 \mathrm{~h}$ (T2) after birth.

\begin{tabular}{lcrr}
\hline & T1 & T2 & $p$-value \\
& Mean (SD) & $0.98(1.23)$ & $<.18(2.25)$ \\
Baseline NFCS score & $0.63(0.87)$ & 5.18 (SD) & $<0.05$ \\
NFCS score with one leg extended & $4.15(2.32)$ & $5.73(1.81)$ & $<0.002$ \\
NFCS score with two legs extended & $4.74(2.23)$ & $49.46(1.84)$ & $<0.001$ \\
Length with one leg extended (cm) & $49.63(1.76)$ & $49.27(1.86)$ & $<0.001$ \\
Length with two legs extended (cm) & $49.40(1.79)$ & $<0.001$ \\
\hline
\end{tabular}

distress to the neonate, accuracy may be influenced by reluctance of the measurer to cause discomfort, even by exerting gentle force. This study confirms that crown-heel measurement technique causes distress to neonates, with NFCS scores similar to those registered during the heel-stick procedure for blood sampling [10]. Measurements with one lower limb fully extended result in significantly less discomfort than with both lower limbs, as conventionally recommended $[5,6]$. This difference is not only statistically significant but also clinically relevant. Taking into account that such a common procedure should be as painless as possible, health professionals should prefer the least distressful technique proven reliable.

Grunau et al. [12] found that neonates that are awake have the highest response to noxious stimuli in comparison to those that are asleep. We started scoring discomfort when the subjects were comfortable after undressing them. The small difference in waking state $(87 \%$ at $\mathrm{T} 1$ vs $96 \%$ at $\mathrm{T} 2)$ is the only explanation for higher discomfort scores on the second day of measurement when less distress with the procedure would be presumed, compared to the first hours after birth which would be more influenced by intrauterine flexion. The baseline NFCS scores differed significantly on both occasions, which made it impossible to compare discomfort scores. Inconsistent findings have been reported on gender differences in NFCS discomfort scores. In concordance with Grunau et al. [12] and Stevens et al. [20], we found no differences in NFCS scores between sexes. Guinsburg et al. [10] found that female newborn infants express more facial features of pain than their male counterparts during capillary puncture and 1 min afterwards. The different NFCS scores between sexes may rely on different invasive and non-invasive procedures assessed in the different studies.

The difference between measuring with one and both lower limbs extended was smaller at approximately $32 \mathrm{~h}$ of age than at approximately $8 \mathrm{~h}$ of age, with a higher correlation similarity coefficient at T2. This may be explained by improved ability of the measurer to extend the lower limbs fully at $32 \mathrm{~h}$ of age. Since special attention was paid to perform measurements keeping both trunk and limb axes parallel and the line between the ileac crests at a right angle with the trunk axis, a greater measured length may be due to achieving a more complete extension with only one lower limb extended. Although statistically significant, the differences found may be of low clinical relevance, since a satisfactory accuracy is also achieved when measuring neonates on the first day after birth.

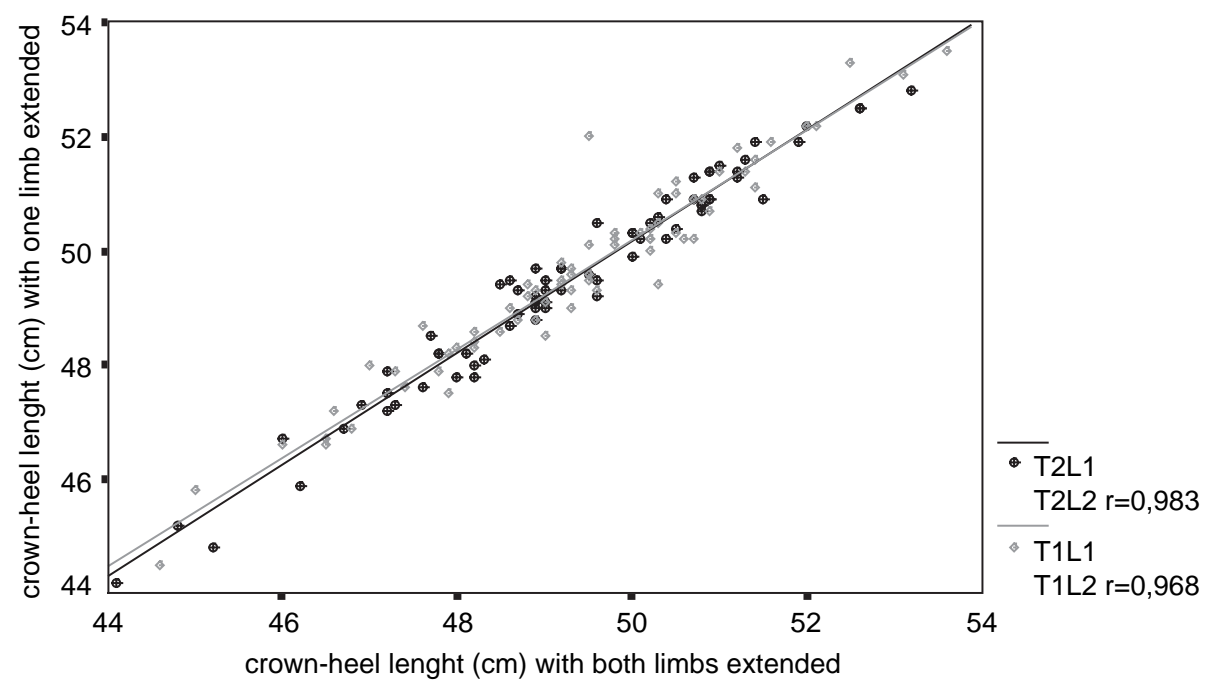

Figure 2. Correlations between length measurements with one (L1) or both extended lower limbs (L2), at approximately 8 (T1) and $32 \mathrm{~h}$ (T2) of life $(n=71)$. Scatter-plot graph with linear regression lines: correlation coefficient $r$ measures correlation between pairs of variables. 
Shinwell et al. found that crown-heel length significantly increases over $2 \mathrm{~d}$ of life $(0.37 \mathrm{~cm}, p=$ 0.001 ), suggesting that this may be a result of the gradual decrease of the intrauterine state of flexion [3]. In our study, no significant differences in length were found between measurements with one and both lower limbs extended at approximately 8 or $32 \mathrm{~h}$ after birth. The differences with Shinwell results may be explained by the fact that we measured the subjects first at approximately $8 \mathrm{~h}$ after birth, while Shinwell et al. measured them within the first $2 \mathrm{~h}$ of life. In contrast to the study by Shinwell et al., our sample had a greater proportion of neonates born by caesarean section, mainly for obstetrical reasons, as the sample was obtained in a referral maternity centre for high-risk pregnancies. Passage through the birth canal during delivery may affect the shape of the skull and therefore the measured length.

In conclusion, measuring crown-heel length in neonates is a distressful procedure. Since it is a very common procedure in general paediatric practice, effort should be made to reduce distress to the neonate as much as possible, with one lower limb extended rather than with both lower limbs extended, without loosing accuracy.

\section{References}

[1] Laron Z. The diagnostic and prognostic importance of neonatal length measurements. Isr Med Assoc J 2000;2:84-5.

[2] Gibson AT, Carney S, Wright NP, Wales JKN. Measurement and the newborn infant. Horm Res 2003;59(Suppl 1):11928.

[3] Shinwell ES, Shlomo M. Measured length of normal term infants changes over the first two days of life. J Pediatr Endocrinol Metab 2003;16:537-40.

[4] Bishop NJ, King FJ, Lucas A. Linear growth in the early neonatal period. Arch Dis Child 1990;65:707-8.

[5] Falkner F. Some introductory concepts of human growth: an overview. Acta Paediatr Scand Suppl 1985;319:17-20.
[6] Gordon CC, Chumlea WC, Roche AF. Stature, recumbent length and weight. In: Lohman TG, Roche AF, Martorell R, editors. Anthropometric standardization reference manual. Champain: Human Kinetic Books; 1988. p. 3-8.

[7] Fletcher MA. Assessment of size and growth. In: Fletcher MA, editor. Physical diagnosis in neonatology. Philadelphia: Lippincott-Raven Publishers; 1998. p. 29-54.

[8] Prins I. Anthropometry in the newborn: a clinical review. Pediatric Rev Commun 1995;8:157-70.

[9] Grunau RE, Oberlander T, Hosti L, Whitfield MF. Bedside application of the Neonatal Facial Coding System in pain assessment of premature neonates. Pain 1998;76:277-86.

[10] Guinsburg R, de Araújo Peres C, Branco de Almeida MF, de Cassia Xavier Balda R, Cassia Berenguel R, Tonelotto J, et al. Differences in pain expression between male and female newborn infants. Pain 2000;85:127-33.

[11] Pereira-da-Silva L, Marçal J, Videira-Amaral JM. The measurement of newborn infants in a Portuguese maternity. Proposal of a model of neonatometer. Acta Pediatr Port 1995;1:81-4.

[12] Grunau RVE, Craig KD. Pain expression in neonates: facial action and cry. Pain 1987;28:395-410.

[13] Grunau RVE, Johnston CC, Craig KD. Neonatal facial and cry responses to invasive and non-invasive procedures. Pain 1990;42:295-350.

[14] Ekman P, Friesen WV. Manual for the Facial Action Coding System. Palo Alto, CA: Consulting Psychologists Press; 1978.

[15] Johnston CC, Strada ME. Acute pain response in infants: A multidimensional description. Pain 1986;24:373-82.

[16] Craig KD, Grumau RE, Aquan-Assee J. Judgement of pain in newborns: facial activity and cry as determinants. Can J Behav Sci 1988;20:442-51.

[17] Hadjistavropoulos HD, Craig HD, Grunau RV. Judging pain in infants: Behavioral, contextual and developmental determinants. Pain 1997;73:319-24.

[18] Doull IJ, McCaughey ES, Bailey BJ, Betts PR. Reliability of infant length measurement. Arch Dis Child 1995;72:520-1.

[19] Johnson TS, Engstrom JL, Haney SL, Mulcrone SL. Reliability of three length measurement techniques in term infants. Pediatr Nurs 1999;25:13-7.

[20] Stevens BJ, Johnston CC, Horton L. Factors that influence the behavioral pain responses of premature infants. Pain 1994;59: $101-9$. 